\title{
Thermal Properties of Lauric- and Stearic Acid Intercalated Layered Double Hydroxides
}

\author{
WALTER WILHELM FOCKE ${ }^{\mathrm{a}}$, NONTETE SUSAN NHLAPO ${ }^{\mathrm{a}}$, LUMBIDZANI MOYO ${ }^{\mathrm{a}}$ AND \\ SABINE MARIE CHARLOTTE VERRYN ${ }^{\mathrm{b}}$ \\ Institute of Applied Materials, ${ }^{\mathrm{a}}$ Department of Chemical Engineering, ${ }^{\mathrm{b}}$ Department of Materials Science and \\ Metallurgical Engineering, University of Pretoria, Lynnwood Road, 0002 Pretoria, South Africa
}

A commercial layered double hydroxide (LDH) with nominal composition $\left[\mathrm{Mg}_{0.689} \mathrm{Al}_{0.311}(\mathrm{OH})_{2}\right]\left(\mathrm{CO}_{3}\right)_{0.156} \cdot \mathrm{zH}_{2} \mathrm{O}$ was intercalated with lauric and stearic acid using a surfactant-assisted method. X-ray diffraction, thermal analysis and infrared spectroscopy confirmed that bilayer-intercalated compounds were formed and that the surfactant (sodium dodecyl sulfate) was not co-intercalated. These compounds shows interesting thermal behavior with two phase transformations observed at elevated temperatures. At temperatures that are significantly higher than the melting points of the corresponding free acids, the alkyl chains assume a disordered liquid-like state within the clay galleries. However, at even higher temperatures the materials become completely amorphous like true melts.

Keywords: Layered Double Hydroxides; Anionic Clays; Intercalation; Lauric; Stearic acid

\section{INTRODUCTION}

Layered double hydroxides (LDH) are the synthetic analogues of the naturally occurring anionic clay mineral hydrotalcite [1]. The general chemical formula is $\left[\mathrm{M}_{1-x}^{I I} \mathrm{M}_{x}^{I I I}(\mathrm{OH})_{2}\right]^{x+} A_{x / y}^{y-} \cdot z \mathrm{H}_{2} \mathrm{O}$ with $\mathrm{M}^{\mathrm{II}}=\mathrm{Mg}, \mathrm{Zn}, \mathrm{Fe}, \mathrm{Co}, \mathrm{Ni}, \mathrm{Cu}$ and $\mathrm{M}^{\mathrm{III}}=\mathrm{Al}, \mathrm{Fe}, \mathrm{Ga}, \mathrm{Cr}[2-4]$. The structure of these compounds consists of trioctahedral metal hydroxide sheets that alternate with interlayers containing anions and water. The brucite-like sheets have a net positive charge $x$ per formula unit owing to isomorphic substitution of some of the divalent cations by trivalent ones. This net positive charge is balanced by an equal negative charge from the interlayer anions [5]. The water molecules occupying the interlayer space are partially oriented owing to hydrogen bond interactions with the anions and the hydroxyl groups on the surface of the octahedral layers [6].

Part of the importance of LDH is based on their ability to exchange anions [7 - 10]. Numerous counterbalancing anions can be used except those that form complexes with the cations present in the octahedral sheets [11]. Thus a wide range of hydrotalcite materials can be tailored for specific applications, e.g. precursors for mixed metal oxide catalysts, absorbents, flame retardant fillers, UV-radiation stabilizers, chloride scavenging thermal stabilizer and polymer nanocomposites [12 -14]. Bringley and Liebert [15] examined the ability of layered materials to sequester and later release molecules of chemical and biological significance.

Synthesis of hydrotalcite-like LDH compounds was pioneered by Feitknecht and Gerber [16], Roy et al. [17], Gastuche et al. [18], Miyata [19, 20] and Mascolo and Marion [21]. The synthesis methods used for preparation of organo-LDH and their potential applications have been comprehensively documented [4, 5, 7, 9, 22 - 24]. They include co-precipitation, ion-exchange, 
LDH reconstruction, and melt reaction methods. Carlino [7] reviewed LDH intercalation methods for carboxylic acids. LDHs can be prepared by direct synthesis methods, e.g. hydrothermal crystallization of gels formed by the co-precipitation of the $\mathrm{M}^{\mathrm{II}}$ and $\mathrm{M}^{\mathrm{III}}$ hydroxides in the presence of the required organic anion [30]. Indirect methods utilize LDH precursors prepared by direct synthesis. Crepaldi et al. [30] identified three main indirect techniques: (i) direct anion exchange; (ii) anion exchange by elimination of the precursor interlamellar species; and (iii) LDH regeneration from a layered double oxide form obtained by calcinations of a suitable precursor. The problem with the latter method is that ion exchange is often incomplete [25]. The degree of stearate intercalation is independent of the anionic exchange capacity (AEC) of the clay [26, 27]: In tightly packed bilayer structures, the amount of intercalated fatty acid significantly exceeds the AEC of the LDH [28].

The carbonate anions in $\mathrm{LDH}-\mathrm{CO}_{3}$ do not readily ion exchange owing to strong electrostatic and hydrogen-bonding interactions. However, Nhlapo et al. [28] were able to prepare bilayer intercalated LDH-fatty acids by using nonionic or anionic surfactants as intercalation aids. This method yields double layer intercalated LDH materials with the fatty acids present as charge neutralizing carboxylate anions and neutral molecules. The total amount of stearate intercalated exceeded the anionic exchange capacity by ca. $140 \%$. This level of intercalation achieves close packing of the chains in the galleries and it is driven by the stabilizing effect of hydrophobic interactions between the chains.

Close-packed double layer fatty acid intercalation of LDH was previously achieved by different methods $[26,27,29]$. However those materials differ fundamentally from those studied presently with respect to the nature of the acid species present in the clay galleries. Borja and Dutta [29] intercalated $\mathrm{Mg}_{3} \mathrm{Al}-\mathrm{LDH}-\mathrm{Cl}$ with fatty acids dissolved in ethanol. Their method yielded materials in which the carboxylic acids $\left(\mathrm{CH}_{3}\left(\mathrm{CH}_{2}\right)_{n} \mathrm{COOH}, n=10,12,14\right)$ are intercalated as neutral molecules with the chloride anions retained as the counter ions. Kanoh et al. [26] and Itoh et al. [27] also used the LDH chloride form as starting material. However, they treated the clay with an alcoholic solution of sodium stearate. In the LDH-stearate materials they prepared in this way, the acid was intercalated as charge neutralizing carboxylates while the excess was intercalated as the corresponding sodium salt.

The study by Borja and Dutta [29] also explored the effect of temperature on the structure and dynamics of the bilayer neutral fatty acid "films" using diffraction, calorimetry, and vibrational spectroscopy. They reported that the d-spacing decreased with temperature and suggested that the "films" become disordered through the formation of kinks and gauche blocks at elevated temperatures. It should be noted that, apart from the acids, their materials also contained significant amounts of ethanol ( $30 \mathrm{wt}$. \%!). The presence of this impurity may have affected the thermal properties of the materials they prepared.

The materials synthesis method described by Nhlapo et al. [28] yields clays that contain both ionized and neutral acid molecules. It is therefore of interest to re-examine the effect of temperature on confined "fatty acid films" comprising a mixture of charged and neutral carboxylic acids. Thus the present paper describes the thermal behavior of $\mathrm{Mg}_{2} \mathrm{Al}-\mathrm{LDH}$-laurate and $\mathrm{Mg}_{2} \mathrm{Al}-\mathrm{LDH}$-stearate prepared by the surfactant-mediation method using sodium dodecylsulphate (SDS) as the surfactant. The nature of the intercalated chains was probed using temperature-scanned DSC, FT-IR, XRD and hot stage microscopy. 


\section{EXPERIMENTAL}

\section{Materials and Reagents}

All the reagents were used without further purifications. LDH-CO 3 (HT-325 grade) was supplied by Chamotte Holdings. It contained silica and magnesium carbonate as minor impurities. Stearic acid (65-90\%) was purchased from Bio-zone chemicals and dodecanoic acid (lauric acid) from Croda Chemicals. Other chemicals and their suppliers were: Sodium dodecylsulphate (SDS, 98\% Fluka); 25\% aqueous ammonia solution (Promark Chemicals); acetic acid (98\% Saarchem), ethanol and acetone (99.9\% and 99\% AR grade, Radchem Laboratory Suppliers), and potassium bromide (Uvasol KBr, Merck).

\section{Sample preparation}

Intercalation experiments were conducted according to the following typical procedure: $20 \mathrm{~g}$ $\mathrm{LDH}-\mathrm{CO}_{3}(0.0852 \mathrm{~mol} \mathrm{Al}), 25.64 \mathrm{~g}$ lauric acid $(0.117 \mathrm{~mol})$ and $40 \mathrm{~g}$ SDS surfactant $(0.139 \mathrm{~mol})$ were suspended in $1000 \mathrm{~mL}$ distilled water. The mixture was maintained at the required reaction temperature, e.g. $70^{\circ} \mathrm{C}$, for 8 hours and then allowed to cool down overnight. $\mathrm{NH}_{4} \mathrm{OH}$ was added to maintain $\mathrm{pH}>10$. This cycle was repeated four times. Two additional portions of lauric acid $(25.64 \mathrm{~g})$ were added after the first two cycles so that the overall total amount was $76.92 \mathrm{~g}$. In the last cycle the mixture was stirred for 8 hours without acid addition. LDH-stearate was prepared in a similar fashion. In this case the reaction temperature was controlled at $80^{\circ} \mathrm{C}$ and a total of 100 $\mathrm{g}$ stearic acid was added. In each case the mixtures were allowed to cool down slowly to ambient temperature. The solids were recovered by centrifugation, washed once with distilled water, four times with ethanol and thereafter once with acetone. After each washing the solids were separated from the liquid by centrifugation. The product was allowed to dry at room temperature.

\section{Characterization}

Hot stage microscopy was performed using a Leica DMRX camera system fitted with a Rheometric Scientific temperature programmer. Temperature was scanned from $25{ }^{\circ} \mathrm{C}$ to $150{ }^{\circ} \mathrm{C}$ at $5^{\circ} \mathrm{C} / \mathrm{min}$. A Mettler Toledo A851 simultaneous TGA/SDTA instrument was used for gravimetric analysis. Powder samples (ca. $10 \mathrm{mg}$ ) were placed in open $70 \mu \mathrm{l}$ alumina pan and heated from $25^{\circ} \mathrm{C}$ to $700^{\circ} \mathrm{C}$ at a scan rate of $10^{\circ} \mathrm{C} / \mathrm{min}$ in air. Differential Scanning Calorimetry (DSC) data was collected on a TA Instruments DSC Q100. 5-10 mg samples were placed in an alumina pan and heated from $-20^{\circ} \mathrm{C}$ to $150^{\circ} \mathrm{C}$ at a rate of $10^{\circ} \mathrm{C} / \mathrm{min}$ and a $\mathrm{N}_{2}$ flow rate of 50 $\mathrm{mL} / \mathrm{min}$.

Infrared spectra were recorded on a Perkin Elmer Spectrum RX I FT-IR system. Data obtained from 20 scans recorded at a resolution of $2 \mathrm{~cm}^{-1}$ were averaged and background-corrected using a pure $\mathrm{KBr}$ pellet. A small amount of sample was sandwiched between $13 \mathrm{~mm}$ diameter $\mathrm{KBr}$ disks and placed into the temperature-controlled sample holder. The temperature was increased at a rate of $10^{\circ} \mathrm{C} / \mathrm{min}$ between temperature settings. On reaching a measurement setting, the sample was allowed to equilibrate for one minute before recording the spectrum.

XRD spectra were recorded on a PANalytical X-pert Pro powder diffractometer with automatic divergence- and receiving slits and an X'celerator detector using Fe filtered Co K-alpha radiation $(0.17901 \mathrm{~nm})$. A back loading preparation method was used. The data was manipulated using X'Pert High Score Plus software. Non-ambient XRD scans were obtained using the same instrument fitted with an Anton Paar HT16 Heating chamber with a Pt-heating filament. Silicon powder (Aldrich 99\% purity) was mixed with the sample as a standard for determination of exact 
peak positions. Samples were scanned between 1 and $40^{\circ}(2 \theta)$ in heating mode at preselected temperatures with a waiting time of 1 minute and measurement time of 6 minutes per scan. The data was corrected for sample displacement using X'Pert Highscore plus software and is presented as variable slit data as that allows for better data visualization, especially at low angles.

TABLE 1 Thermogravimetric results and estimates for the degree of carboxylate intercalation

\begin{tabular}{lccc}
\hline Sample & $\begin{array}{c}\text { Residual mass (wt. \%) at: } \\
\text { Identity }\end{array}$ & $\begin{array}{c}\text { Carboxylate/Al } \\
\text { Mol ratio }\end{array}$ \\
\hline HT325 & 97.8 & 58.3 & \\
LDH-stearate & 95.6 & 12.5 & 3.5 \\
LDH-laurate & 91.4 & 17.7 & 3.0 \\
\hline
\end{tabular}

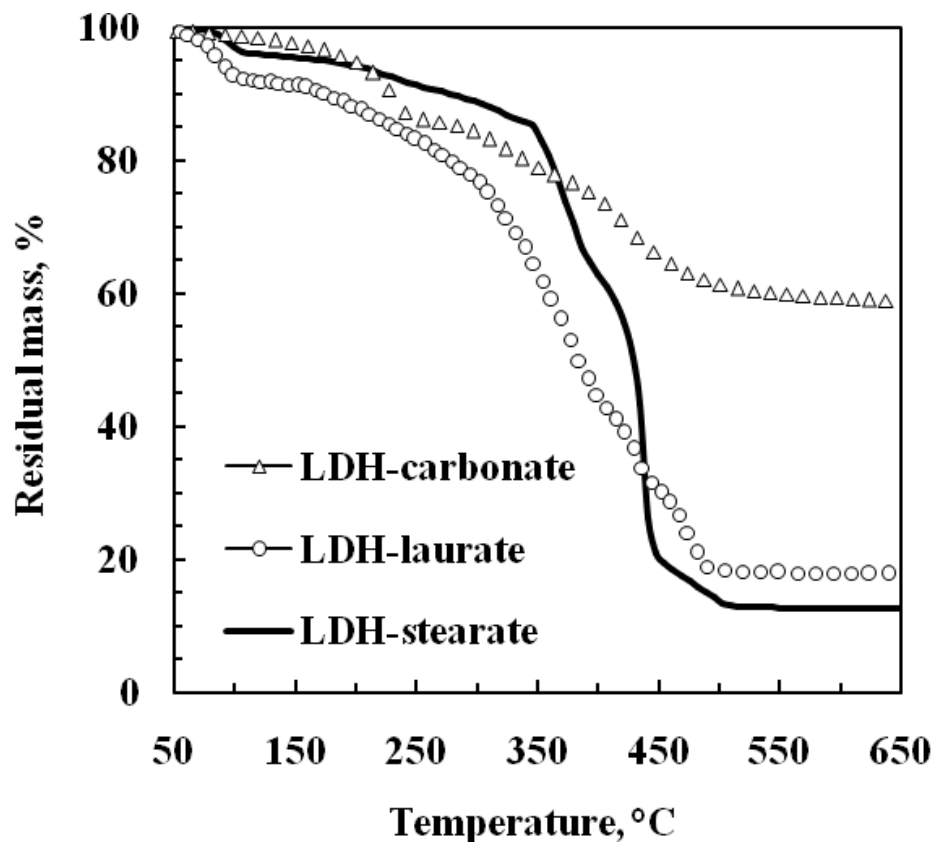

FIGURE 1 Thermogravimetric (TG) mass loss curves for $\mathrm{LDH}_{-} \mathrm{CO}_{3}, \mathrm{LDH}-$ laurate and LDHstearate obtained at a scan rate of $10^{\circ} \mathrm{C} / \mathrm{min}$ in an air atmosphere.

\section{RESULTS}

The TG traces Figure 1 show that mass loss in all the compounds proceeds in several steps. These consecutive events are commonly attributed to the loss of interlayer water, dehydroxylation and a combination of dehydroxylation-decarbonation/-decarboxylation reactions respectively [28].

Above $550{ }^{\circ} \mathrm{C}$, the residues correspond to mixtures of the metal oxides $\mathrm{MgO}$ and $\mathrm{Al}_{2} \mathrm{O}_{3}$. Thus for the $\mathrm{LDH}-\mathrm{CO}_{3}$, the expected and experimentally observed values for the TG residues after the final degradation step are $56.3 \%$ and $58.3 \%$ (at $\left.\mathrm{T}=700^{\circ} \mathrm{C}\right)$ respectively [2]. Table 1 lists the TG data and together with estimates of the number of carboxylate chains intercalated per aluminum atom in the clay. These calculations were based on the differences in mass observed at temperatures of $150{ }^{\circ} \mathrm{C}$ and $700{ }^{\circ} \mathrm{C}$ relative to the corresponding values for the $\mathrm{LDH}-\mathrm{CO}_{3}$. 


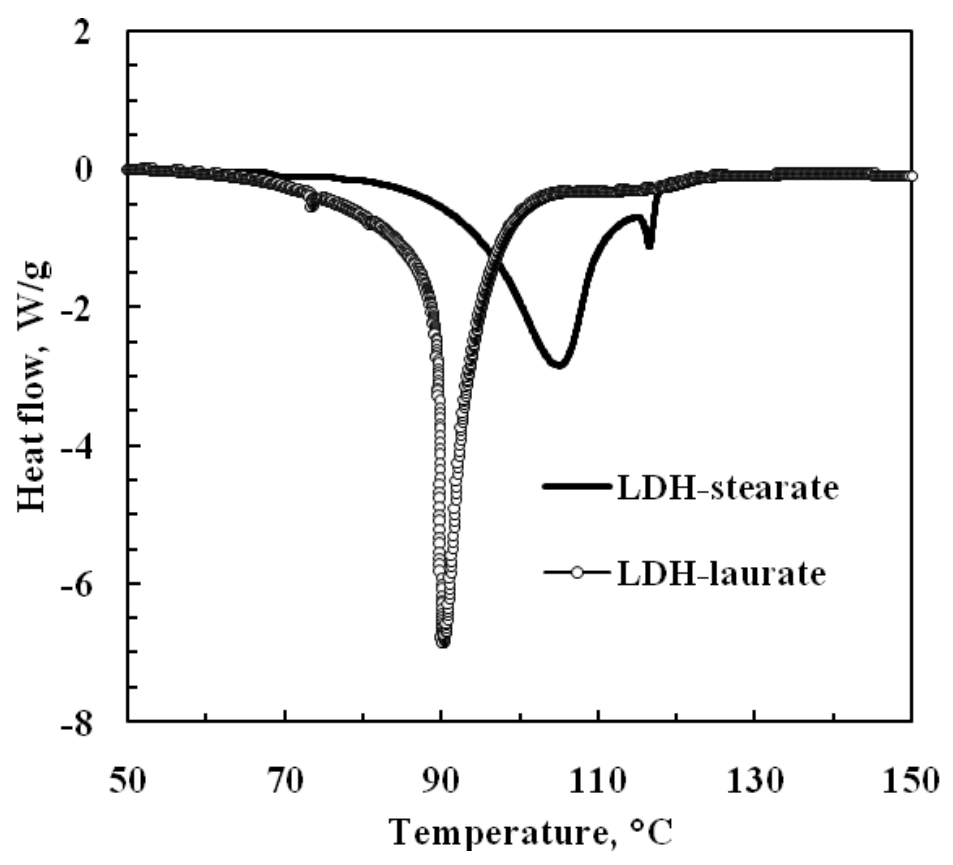

FIGURE 2 DSC endotherms of LDH-laurate and LDH-stearate at a scan rate of $10^{\circ} \mathrm{C} / \mathrm{min}$ in an air atmosphere.

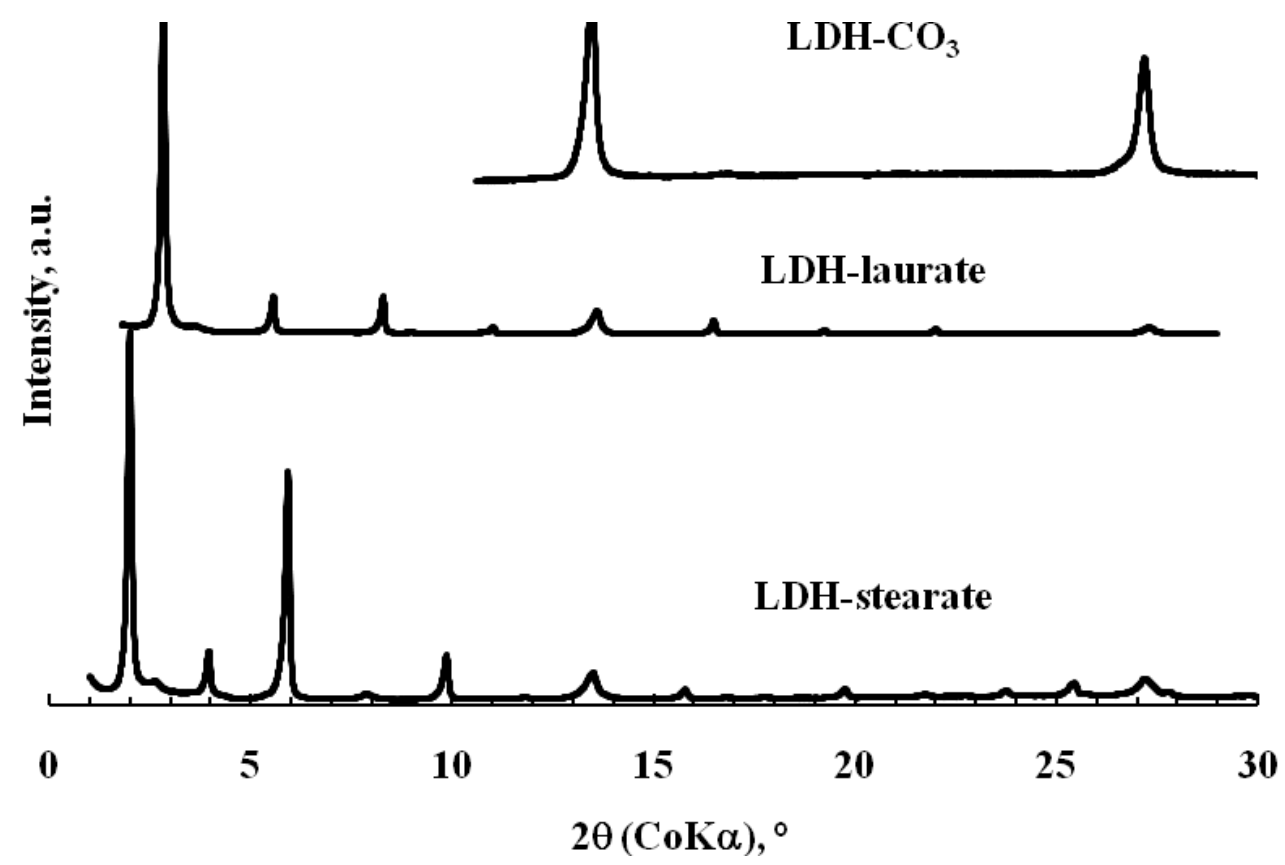

FIGURE 3 Powder XRD spectra for $\mathrm{LDH}-\mathrm{CO}_{3}$, LDH-laurate and LDH-stearate. 


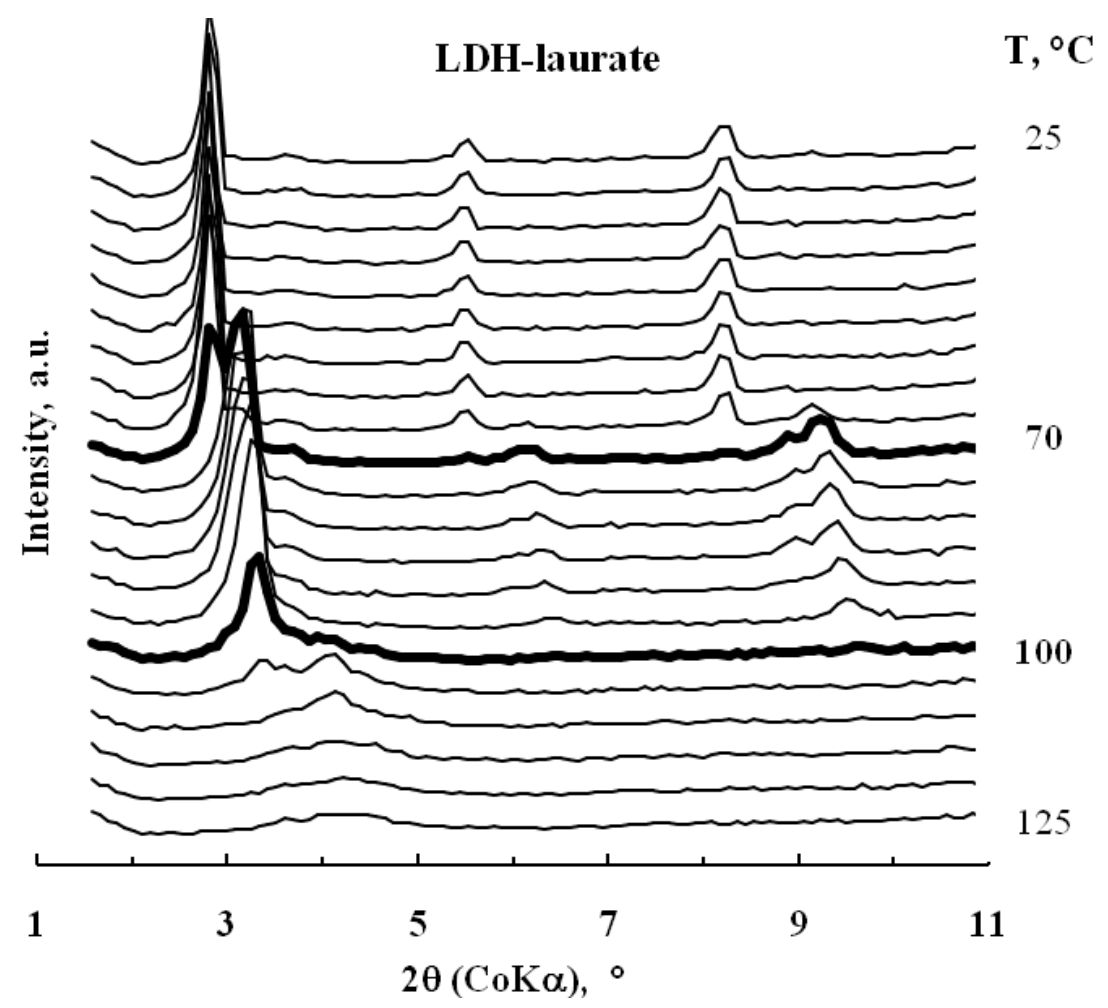

FIGURE 4 The effect of temperature on the X-ray diffractograms of LDH-laurate.

Figure 2 shows the endotherms observed in the DSC scans. The LDH-laurate shows a single, well-developed endothermic event with a peak near $90^{\circ} \mathrm{C}$. The LDH-stearate sample features a dominant endotherm centered at $105^{\circ} \mathrm{C}$ and a smaller endothermic event with a peak at $116^{\circ} \mathrm{C}$. We attribute the first endotherm peak in each case to a "melting" of the interlayer chains. Neat lauric acid melts at ca. $46{ }^{\circ} \mathrm{C}$ while neat stearic acid melts at ca. $72{ }^{\circ} \mathrm{C}$. The observed onset temperatures are significantly higher than these values. This increase in the melting temperature is attributed to the two-dimensional confinement imposed by the clay sheets.

The small size of the crystals made it difficult to observe melting events under the microscope in the absence of polarizing filters. Movement of LDH-laurate crystals was observed at about $86{ }^{\circ} \mathrm{C}$ and "melting" of the smaller crystals appeared to take place from $90^{\circ} \mathrm{C}$. Movement of LDHstearate crystal particles was observed at $80^{\circ} \mathrm{C}$ and "melting" commenced at ca. $117^{\circ} \mathrm{C}$. These results suggest that the powder particles appear "molten" only towards the end of the main endothermic event observed in the respective DSC scans.

The powder XRD spectra for $\mathrm{LDH}-\mathrm{CO}_{3}$, $\mathrm{LDH}$-laurate and $\mathrm{LDH}$-stearate are presented in Figure 3 . It is clear that both intercalates also contain minor amounts of unreacted $\mathrm{LDH}-\mathrm{CO}_{3}$. The length of the fully extended fatty acid chains slightly exceeds $0.127 n$, where $n$ indicates the number of methylene groups in the alkyl chain. This translates into lengths of $1.40 \mathrm{~nm}$ and $2.16 \mathrm{~nm}$ for laurate and stearate respectively. The d-spacings were estimated at $0.76 \mathrm{~nm}, 3.6 \mathrm{~nm}$ and $5.1 \mathrm{~nm}$ for $\mathrm{LDH}-\mathrm{CO}_{3}, \mathrm{LDH}$-laurate and $\mathrm{LDH}$-stearate in that order. The latter two values are thus consistent with bilayer intercalation of the carboxylic acids as previously found [26-28,29]. This is also confirmed by quantity of fatty acid intercalated in each case as determined from the TG data. 


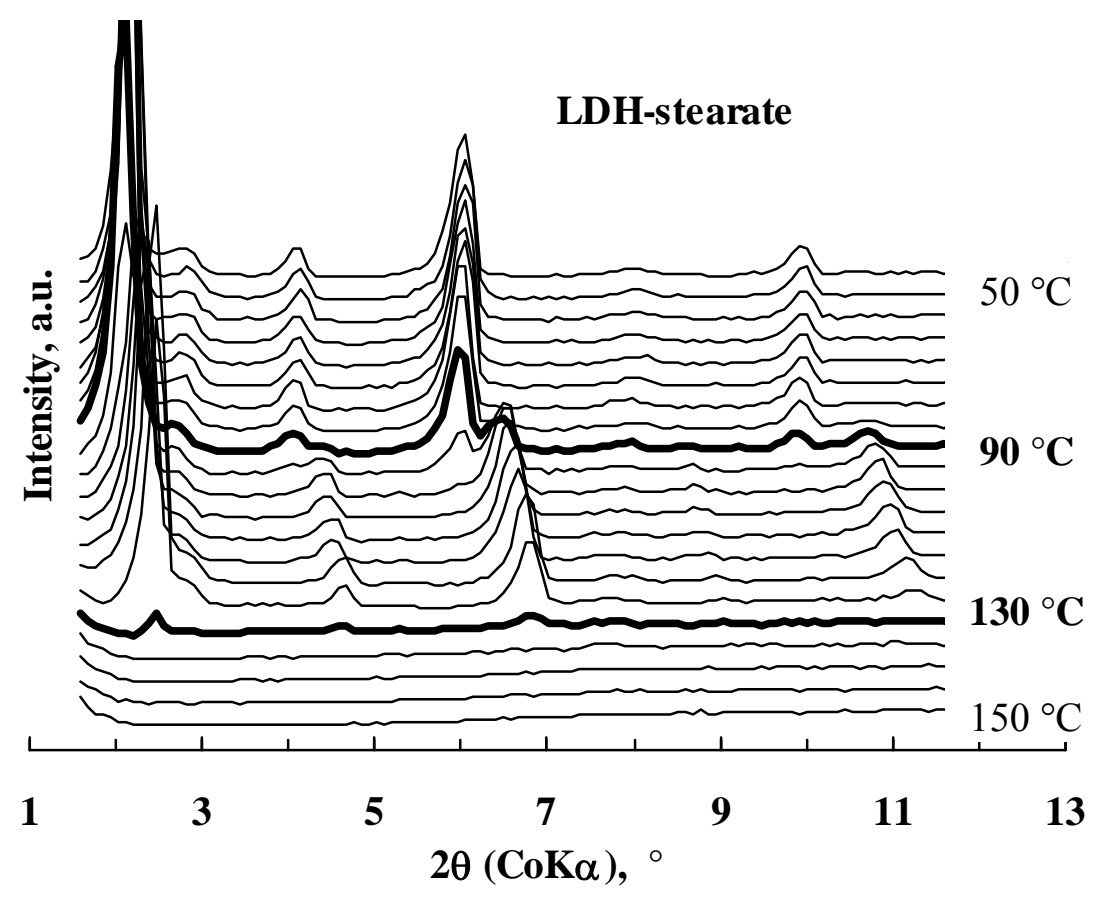

FIGURE 5 The effect of temperature on the X-ray diffractograms of LDH-stearate.

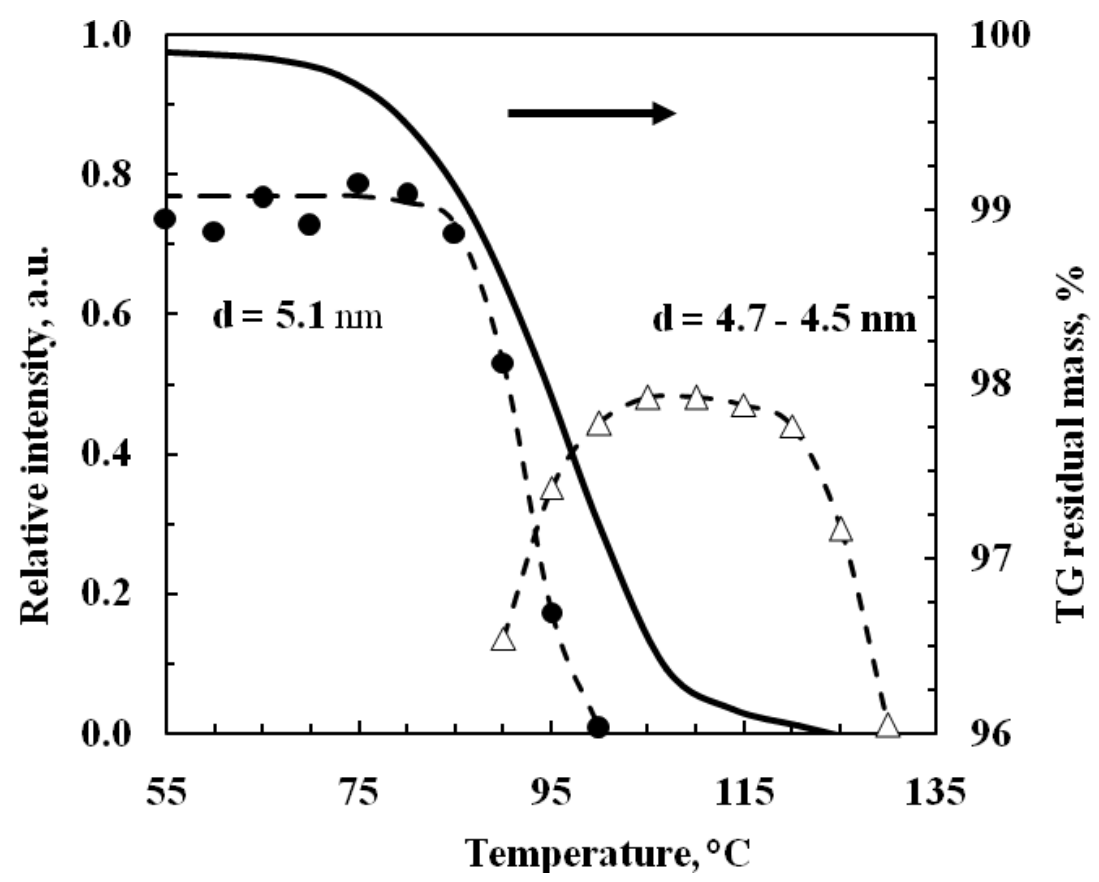

FIGURE 6 The effect of temperature on the relative intensity of the basal reflection in the XRD spectrum compared to the TG mass loss in the same temperature range for LDH-stearate. 


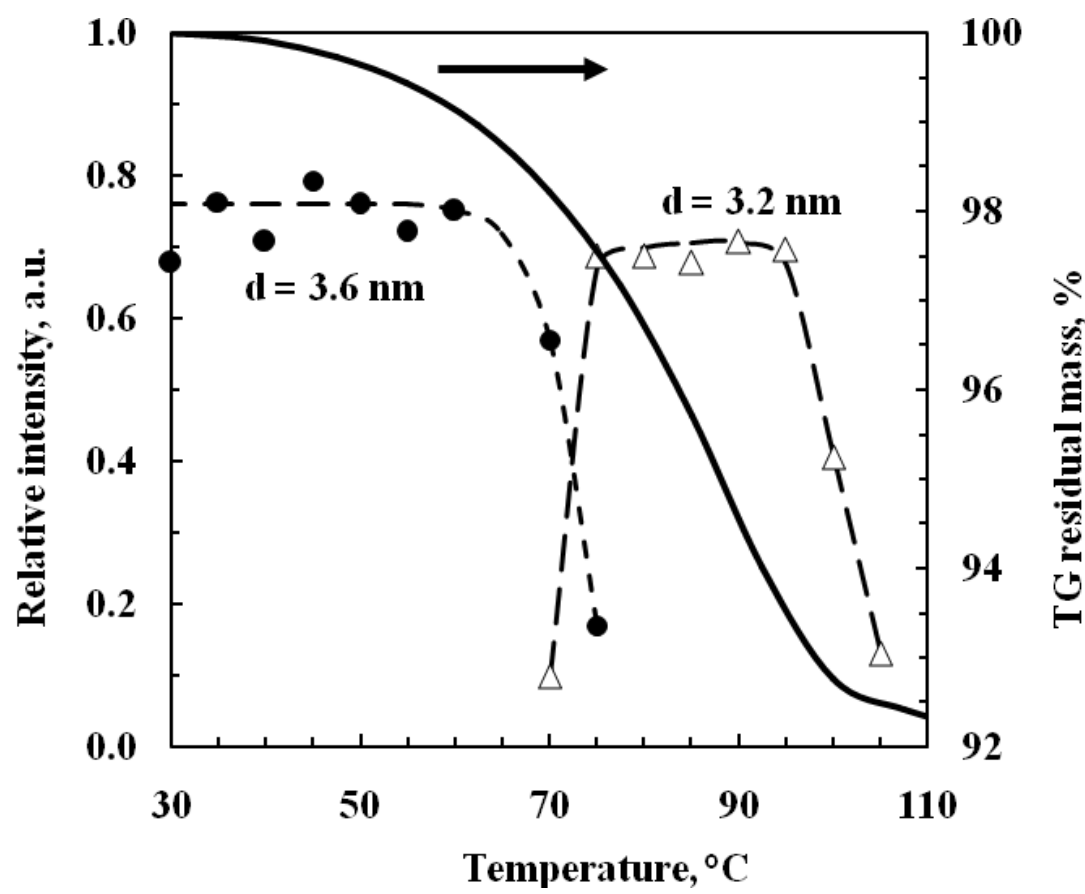

FIGURE 7 The effect of temperature on the relative intensity of the basal reflection in the XRD spectrum compared to the TG mass loss in the same temperature range for LDH-laurate.

Figure 4 shows the effect of temperature on the XRD spectrum of LDH-laurate. An abrupt transition is observed at a temperature of $70{ }^{\circ} \mathrm{C}$. This change is characterized by a reduction of the d-spacing from $3.6 \mathrm{~nm}$ to approximately $3.2 \mathrm{~nm}$. Above $100{ }^{\circ} \mathrm{C}$ the peaks characteristic of the intercalated phase disappear. Similar observations apply to the LDH-stearate sample as shown in Figure 5. In this case the transition to the intermediate phase occurs at ca. $90{ }^{\circ} \mathrm{C}$ and the material becomes amorphous above $120^{\circ} \mathrm{C}$. Figure 6 and Figure 7 show plots of the effect of temperature on the intensity of the basal reflection superimposed on the TG mass loss curves. These plots suggest that the transition to a lower basal spacing may, at least in part, be caused by the loss of interlayer water.

The FTIR spectra for the organic modified clays did not feature the sulfate peak expected at 1210 $\mathrm{cm}^{-1}[30]$. This confirms that the surfactant (SDS) did not co-intercalate with the lauric or stearic acids. The FTIR spectra shown in Figure 8 feature strong bands near $2920 \mathrm{~cm}^{-1}$ and $2850 \mathrm{~cm}^{-1}$. These arise from the $\mathrm{CH}_{2}$ asymmetric $\left(v_{\text {as }}\left(\mathrm{CH}_{2}\right)\right)$, and symmetric $\left(v_{\mathrm{s}}\left(\mathrm{CH}_{2}\right)\right)$ stretch modes, respectively. Vaia et al. [31] proposed the use of the $v_{\text {as }}\left(\mathrm{CH}_{2}\right)$ band to probe the nature of the interlayer chain structures. The wavenumber and the width of this band are very sensitive to the gauche/trans conformer ratio and the packing density of the methylene chains. It varies from $2916.8 \mathrm{~cm}^{-1}$ for the methylene chains in the all-trans ordered state in crystalline stearic acid to $2928.9 \mathrm{~cm}^{-1}$ when the chains are in a liquid-like environment [31]. The peak positions of the methylene asymmetric bands found for the present organoclays are presented in Figure 9. They show a shift from the value observed for pure crystalline stearic acid $\left(2916.8 \mathrm{~cm}^{-1}\right)$ to higher values of 2921 $\mathrm{cm}^{-1}$ and $2925 \mathrm{~cm}^{-1}$ for LDH-stearate and LDH-laurate respectively. This shift is consistent with an increase in conformational disorder in the intercalated chains. It also suggests that a greater degree of disorder in the laurate chains as compared to the longer stearate chains. While this confirms a 
disordered structure, the intermediate wavenumber values suggests that the chains nevertheless retained a degree of order above the transition temperature, i.e. that they are not completely liquidlike.

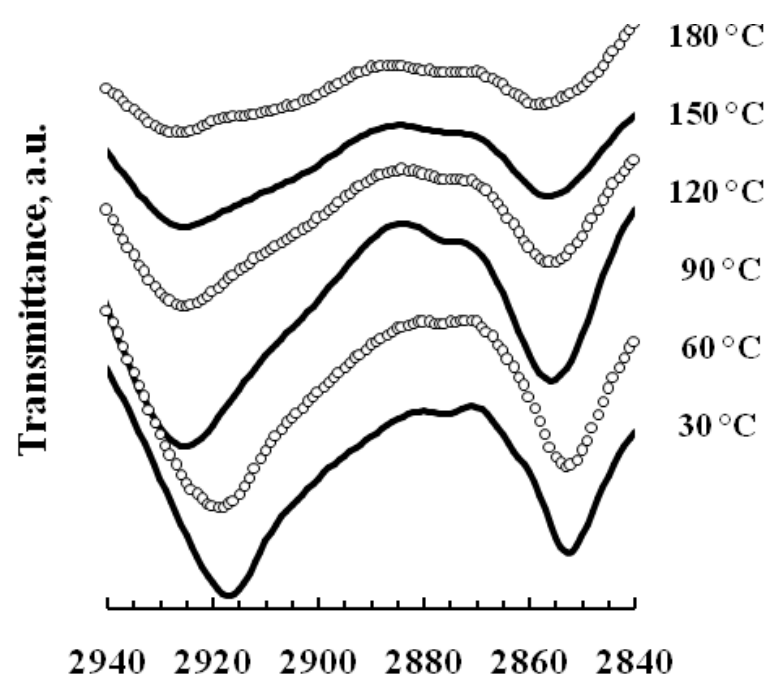

Wavenumber, $\mathbf{c m}^{-1}$

A

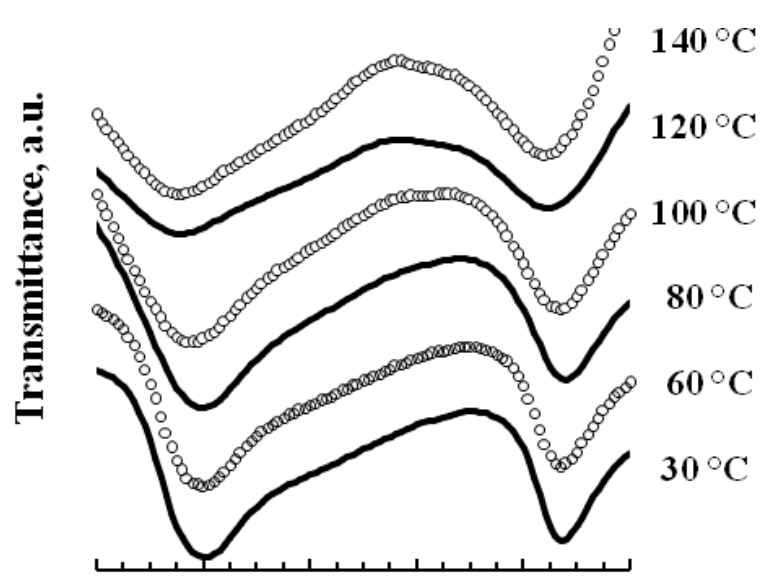

294029202900288028602840

Wavenumber, $\mathbf{c m}^{-1}$

$\mathrm{B}$

FIGURE 8 The effect of temperature on the FT-IR spectra for (A) LDH-laurate and (B) LDHstearate.

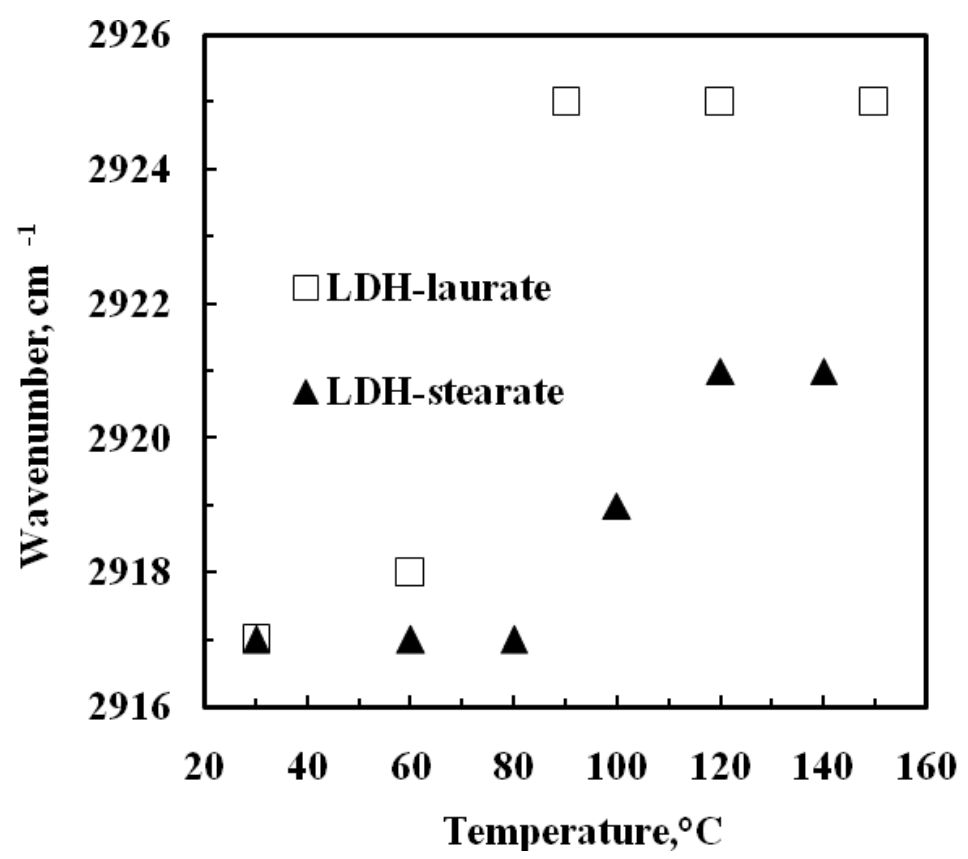

FIGURE 9 The effect of temperature on the peak position of the $v_{\text {as }}\left(\mathrm{CH}_{2}\right)$ band in the FT-IR spectra for LDH-laurate and LDH-stearate. 


\section{DISCUSSION AND CONCLUSION}

The fatty acid anions are introduced up to the clay AEC level by an ion exchange mechanism with the alternative intercalation procedures developed by by Kanoh et al. [26], Itoh et al. [27] and Nhlapo et al. [28]. As such they are electrostatically "attached" to the clay surfaces [32]. The "excess" fatty acid molecules are intercalated as neutral molecules or as the corresponding salts together with their (hydrated) counterions [26 - 28]. The incorporation of the excess fatty acid is driven by the so-called hydrophobic interactions [33]. Dense close-packing of the surfactants in the galleries improves the van der Waals interactions between long alkyl chains [27]. Denser packing also requires better charge shielding of the same-charge surfactant head groups.

The present results indicate that the intercalated chains abruptly assume a quasi-disordered state at temperatures that are similar to those indicated by Borja and Dutta [29]. It should be recalled that their LDH intercalates comprised neutral fatty acids only with chloride anions providing the charge balancing functionality. This means that the transition temperatures of intercalated longchain fatty acids films is virtually independent of the state of the acid, i.e. whether fully neutral, or a mixture of anions and neutral molecules.

Temperature scanned XRD and FTIR data indicates that the intercalated chains undergo an orderdisorder phase transition at elevated temperatures. The driving force can be attributed to the tendency of the chain-extended fatty acids to assume entropically favored disordered conformations as is the case when the free acids melt. The observed transition temperatures were ca. $70{ }^{\circ} \mathrm{C}$ and $90^{\circ} \mathrm{C}$ for the laurate and stearate intercalated $\mathrm{LDH}$ respectively. As expected, these temperatures are significantly higher than the corresponding melting points of the free acids (46 ${ }^{\circ} \mathrm{C}$ for lauric acid and $72{ }^{\circ} \mathrm{C}$ for stearic acid). DSC and XRD studies, not reported here, indicate that this transition is reversible to some extent. However, when the samples are heated to even higher temperatures, i.e. beyond $100{ }^{\circ} \mathrm{C}$ or $125^{\circ} \mathrm{C}$ for laurate and stearate respectively, they become completely X-ray amorphous and do not re-crystallize on cooling [28].

Thus we propose that the fatty acid chains in $\mathrm{Mg}_{2} \mathrm{Al}-\mathrm{LDH}$-laurate and $\mathrm{Mg}_{2} \mathrm{Al}$-LDH-stearate actually undergo a melt-like phase transition at elevated temperatures. Above the melting point they assume a liquid-crystalline "rotator" state owing to the localization of the ionized head group and the two-dimensional confinement imposed by the planar clay sheets. At even higher temperatures the LDH-fatty acid based materials become XRD-amorphous.

\section{Acknowledgements}

Financial support for this research, from the Institutional Research Development Program (IRDP), the South African Cooperation Fund for Scientific and Technological Developments (NEPAD) and the THRIP program of the Department of Trade and Industry and the National Research Foundation of South Africa is gratefully acknowledged.

\section{REFERENCES}

[1] W. T. Reichle. Chemtech, 58, (1986).

[2] S. Miyata, T. Kumura. Chem. Lett., 843, (1973).

[3] W. T. Reichle. Solid State Ionics, 22, 135, (1986). 
[4] M. A. Aramendía, V. Borau, C. Jiménez, J. M. Marinas, J. R. Ruiz, F. J. Urbano. J. Solid State Chem., 168, 156, (2002).

[5] F. Cavani, F. Trifirò, A. Vaccari. Catal. Today, 11, 173, (1991).

[6] G. Marcelin, N. J. Stockhausen, J. F. M. Post, A. Schutz. J. Phys. Chem. 93, 4646, (1989).

[7] S. Carlino. Solid State Ionics, 98, 73, (1997).

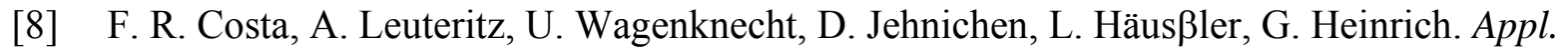
Clay Sci., 38, 153, (2008).

[9] G. R. Williams, D. O'Hare. J. Mater. Chem., 16, 3065, (2006).

[10] J. Zhang, F. Zhang, L. Ren, D. G. Evans, X. Duane. Mater. Chem. Phys., 85, 207, (2004).

[11] A. Vaccari. Catal. Today, 41, 53, (1998).

[12] H. Fischer. Mater. Sci. Eng., C23, 763, (2003).

[13] F. Leroux, J.-P. Besse. Chem. Mater., 13, 3507, (2001).

[14] M. Zammarano, S. Bellayer, J. W. Gilman, M. Franceschi, F. L. Beyer, R. H. Harris, S. Meriani. Polymer, 47, 652, (2006).

[15] J. F. Bringley, N. B. Liebert. J. Dispersion Sci. Technol., 24, 589, (2003).

[16] W. Feitknecht. Helv. Chim. Acta., 25, 555, (1942).

[17] D. M. Roy, R. Roy, E. F. Osborn. Amer. J. Sci., 28, 50, (1953).

[18] M. C. Gastuche, G. Brown, M. M. Mortland. Clay Miner., 7, 177, (1967).

[19] S. Miyata. Clays Clay Miner., 23, 369, (1975).

[20] S. Miyata, A. Okado. Clays Clay Miner., 25, 14, (1977).

[21] G. Mascolo. Appl .Clay Sci., 10, 21, (1995).

[22] D. G. Evans, X. Duan. Chem. Commun., 485, (2006).

[23] U. Costantino, V. Ambrogi, M. Nocchetti, L. Perioli. Microporous Mesoporous Mater., 107, 16, (2008).

[24] L. Moyo, N. Nhlapo, W. W. Focke. J. Mater. Sci., 43, 6144, (2008).

[25] M. Meyn, K. Beneke, G. Lagaly. Inorg. Chem., 29, 5201, (1990).

[26] T. Kanoh, T. Shichi, K. Takagi. Chem. Lett., 117, (1999).

[27] T. Itoh, N. Ohta, T. Shichi, T. Yui, K. Takagi. Langmuir, 19, 9120, (2003).

[28] N. Nhlapo, T. Motumi, E. Landman, S. M. C. Verryn, W. W. Focke. J. Mater. Sci., 43, 1033, (2008).

[29] M. Borja, K. Dutta. J. Phys. Chem., 96, 5434, (1992).

[30] E. L. Crepaldi, P. C. Pavan, J. B. Valim. Chem. Commun., 155, (1999).

[31] R. Vaia, R. Teukolsky, E. Giannelis. Chem. Mater., 6, 1017, (1994).

[32] G. Lagaly. Solid State Ionics, 22, 43, (1986).

[33] D. Chandler. Nature, 437, 640, (2005). 